\title{
Profile of gene expression changes during estrodiol-17 $\beta$-induced feminization in the Takifugu rubripes brain
}

\author{
Xufang Shen ${ }^{1,2}$, Hongwei Yan ${ }^{3^{*}}$, Jieming Jiang ${ }^{2,3}$, Weiyuan $\mathrm{Li}^{3}$, Yuyu Xiong ${ }^{2,4}$, Qi Liu ${ }^{4^{*}}$ and Ying Liu ${ }^{2,4}$
}

\begin{abstract}
Background: As the critical tissue of the central nervous system, the brain has been found to be involved in gonad development. Previous studies have suggested that gonadal fate may be affected by the brain. Identifying brainspecific molecular changes that occur during estrodiol-17 $\left(E_{2}\right)$-induced feminization is crucial to our understanding of the molecular control of sex differentiation by the brains of fish.

Results: In this study, the differential transcriptomic responses of the Takifugu rubripes larvae brain were compared after $E_{2}$ treatment for 55 days. Our results showed that 514 genes were differentially expressed between $E_{2}$-treated$X X(E-X X)$ and Control-XX (C-XX) T. rubripes, while 362 genes were differentially expressed between $E_{2}$-treated-XY (E-XY) and Control-XY (C-XY). For example, the expression of cyp19a1b, gnrh1 and pgr was significantly up-regulated, while $s t, s l$, tsh $\beta, p r l$ and pit-1, which belong to the growth hormone/prolactin family, were significantly downregulated after $E_{2}$ treatment, in both sexes. The arnt11, bhlbe, nr1d2, per1b, per3, cry1, cipc and ciart genes, which are involved in the circadian rhythm, were also found to be altered. Differentially expressed genes (DEGs), which were identified between E-XX and C-XX, were significantly enriched in neuroactive ligand-receptor interaction, arachidonic acid metabolism, cytokine-cytokine receptor interaction and the calcium signaling pathway. The DEGs that were identified between E-XY and C-XY were significantly enriched in tyrosine metabolism, phenylalanine metabolism, arachidonic acid metabolism and linoleic acid metabolism.
\end{abstract}

Conclusion: A number of genes and pathways were identified in the brain of $E_{2}$-treated T. rubripes larvae by RNAseq. It provided the opportunity for further study on the possible involvement of networks in the brain-pituitarygonadal axis in sex differentiation in T. rubripes.

Keywords: Takifugu rubripes, Brain, Estradiol-17ß, Sex differentiation, Transcriptome analysis

\footnotetext{
*Correspondence: yanhongwei_1985@hotmail.com; liuqisunson@163.com

${ }^{3}$ College of Fisheries and Life Science, Dalian Ocean University, Dalian

116023, Liaoning, China

${ }^{4}$ College of Marine Science and Environment Engineering, Dalian Ocean

University, Dalian 116023, Liaoning, China

Full list of author information is available at the end of the article
}

(c) The Author(s). 2021 Open Access This article is licensed under a Creative Commons Attribution 4.0 International License, which permits use, sharing, adaptation, distribution and reproduction in any medium or format, as long as you give appropriate credit to the original author(s) and the source, provide a link to the Creative Commons licence, and indicate if changes were made. The images or other third party material in this article are included in the article's Creative Commons licence, unless indicated otherwise in a credit line to the material. If material is not included in the article's Creative Commons licence and your intended use is not permitted by statutory regulation or exceeds the permitted use, you will need to obtain permission directly from the copyright holder. To view a copy of this licence, visit http://creativecommons.org/licenses/by/4.0/ The Creative Commons Public Domain Dedication waiver (http://creativecommons.org/publicdomain/zero/1.0/) applies to the data made available in this article, unless otherwise stated in a credit line to the data. 


\section{Background}

Sex determination and differentiation are the most essential processes for species reproduction [1]. Sex determination is defined as the developmental process by which the sex is established. Gonadal sex differentiation is defined as the process during which the undifferentiated gonad develops into either an ovary or a testis after the determination of sex [2]. Since sexual dimorphism (such as body size and growth rate) is common in fish, elucidating the mechanism involved in sex determination and differentiation, which may lead to the development of a sex control technique, is of great commercial interest in the aquaculture industry [3]. Moreover, as the largest group of vertebrates, fish display the greatest diversity of sexual phenotypes and are considered excellent models for the investigation of mechanisms involved in sex determination, differentiation, and sexual plasticity. Unlike mammals, sex determination and differentiation are tremendously complex and flexible in fish and the sexual fate of fish has been proven to be affected by exogenous factors (such as social dynamics, temperature, light conditions, density, $\mathrm{pH}$, stress and hormones) [36]. Among those factors, estrogens are conserved and are known to be required for ovarian differentiation and maintenance of the female phenotype [6]. Prior to sexual differentiation, the administration of estrodiol-17 $\beta\left(\mathrm{E}_{2}\right)$ can induce sex reversal (male-to-female) in fish [7, 8]. In fish, estrogens are synthesized by the aromatization of androgens, through cytochrome P450 aromatase, which is mainly encoded by cyp19a1a/b [9]. Previous studies have shown that treatment with an aromatase inhibitor and knockout of cyp19a1a can result in sex reversal in the female [10-12]. $E_{2}$ treatment methods have been widely applied to sex ratio control, in particularly with respect to establishing a monosex population to understand the roles of endocrine and genetic factors regulating sex determination and differentiation in academic research [13-16].

Takifugu rubripes, which is commonly known as the tiger puffer or torafugu, is one of the most popular marine-cultured species in Asia. It is famous for its umami taste and has been available in local Chinese markets since 2016. Tiger puffer aquaculture is mainly distributed across the north coast of China, and the production of farmed pufferfish was over 10, 000 metric tons in 2020 (data from China Fisheries Statistics 2021). More than $90 \%$ of farmed tiger puffers are exported to Japan and South Korea. Since T. rubripes testis is a delicacy and ovaries quite poisonous, male torafugu are more expensive and popular than female torafugu. Hence, monosex male production is desirable in aquaculture. Moreover, T. rubripes is considered as an ideal model for investigating the molecular mechanisms that underlie sex determination and differentiation as it has a relatively small and compact genome, when compared to other vertebrates $[17,18]$.

T. rubripes is a gonochoristic fish and with an $\mathrm{XX} / \mathrm{XY}$ sex determination system and an allelic variation in the amhr2 gene (the AMH receptor) that has been shown to be responsible for maleness [18]. The process of gonadal development in $T$. rubripes and the expression profiles of genes related to the sex differentiation process have been described in previous studies [19-21]. Intercrosses between $E_{2}$-induced generate pseudo female and normal males resulted in the supermale (YY). In T. rubripes, YY males can be used to produced monosex male for the study of gonadal sex differentiation and increasing interest in commercial production. Although whether the sex reversed XY or XX torafugu are fertile or not has not been confirmed until now, it has been demonstrated that treatment of XX T. rubripes with aromatase inhibitor (fadrozole or letrozole) results in the inhibition of ovarian cavity formation [8, 20, 22]. Treatment of genetically XY T. rubripes with $\mathrm{E}_{2}$, prior to morphological sex differentiation, can induce feminization. Several genes involved in $\mathrm{E}_{2}$-induced feminization in the gonads of $T$. rubripes have been characterized in our previous study [22].

Prior to differentiation of the gonads, sexual differences exist in non-gonadal tissues as well as the germline. Thus, these differences are created up-stream of gonadal differentiation [2325]. As the critical tissue of the central nervous system, the brain has been found to be involved in germline development, and the differential development of the two sexes could be the result of differential gene expression in the brain, prior to the formation of the gonads [24-29]. Several sexually dimorphic markers or genes have been identified in the brains of vertebrates [30-36]. Although sex differences in the brain are often presumed to be a consequence of gonadal sex, rather than the cause [37], sex differentiation in the brain is a highly complicated process in lower vertebrates. Previous studies have suggested that gonadal fate may be affected by the brain. For example, forebrain transplants between male and female Japanese quail embryos, before sexual differentiation, disrupted testis function [38, 39]. Perceived social changes can also induce sexual transitions via intersection of the hypothalamicpituitary-interrenal pathway and hypothalamic-pituitary-gonad pathway before sex differentiation in some sequentially hermaphroditic coral reef fish [40]. In zebrafish (Danio rerio), luteinizing hormone beta subunit $(\operatorname{lh} \beta)$ /follicle stimulating hormone beta subunit $(f \operatorname{sh} \beta)$ double knock out resulted in all male fish, whilst gene disruption of $f s h r$, but not $l h c g r$, resulted in masculinization into males and a complete failure of follicle activation $[41,42]$. Until now, unlike gonadal sex differentiation, the mechanisms that underlie the sexual differentiation of the brain have not been completely defined. Identification of genes related to sex differentiation in the brain may facilitate studies of gene interaction between the gonads and brain, which control sex differentiation. However, few studies have focused on 
gene expression changes in the brain during the process of sex differentiation, particularly during the process of sex steroid hormone-induced feminization or masculinization in fish species such as the T. rubripes [29].

We previously reported the sexually dimorphic expression profile of genes in $T$. rubripes brain [43]. In this study, transcriptomic analysis of brains from the control and $E_{2}$-treated groups was then performed. This study aimed to identify target genes and pathways that are involved in the development of $T$. rubripes brains and that responded to $E_{2}$ administration. The data may provide new insights into the mechanism of sex differentiation in the brain and may indicate how estrogen affects gene expression in the brain.

\section{Results}

Histological evaluation of gonadal development

Figure 1 shows the results of the histological analysis of the gonads. As reported by Yan et al., sex reversed larvae were not observed in the control groups [22]. Gonads from the C-XX group occupied the ovarian cavities, which were filled with a small number of oocytes and a large number of oogonia, closely arranged on the oviposition plate. Gonads from the C-XY group were filled with spermatogenic cells at different developmental stages (Fig. 1a and $\mathrm{b}$ ). However, gonads from the $\mathrm{E}_{2}$-immersed group were smaller than those from the control group. In addition, exposure to $E_{2}$ obviously induced the feminization of testes, and a deformed ovarian cavity was observed in all $E_{2}$-treated XY torafugu (Fig. 1c and d).

\section{Illumina sequencing and mapping, and identification of global DEGs, in response to $E_{2}$ treatment}

$528,862,430$ total reads were obtained from all library. After raw reads filtering, 43,622,952 (C-XX_1), 44,436,616 (C-XX_2), 42,850,608 (C-XX_3), 42,851,086 (C-XY_1), 45,072,134 (C-XY_2), 45,005,800 (C-XY_3), 43,442,122 (E-XX_1), 39,629,744 (E-XX_2), 48,253,210 (E-XX_3), 46,193,034 (E-XY_1), 42,700,218 (E-XY_2)

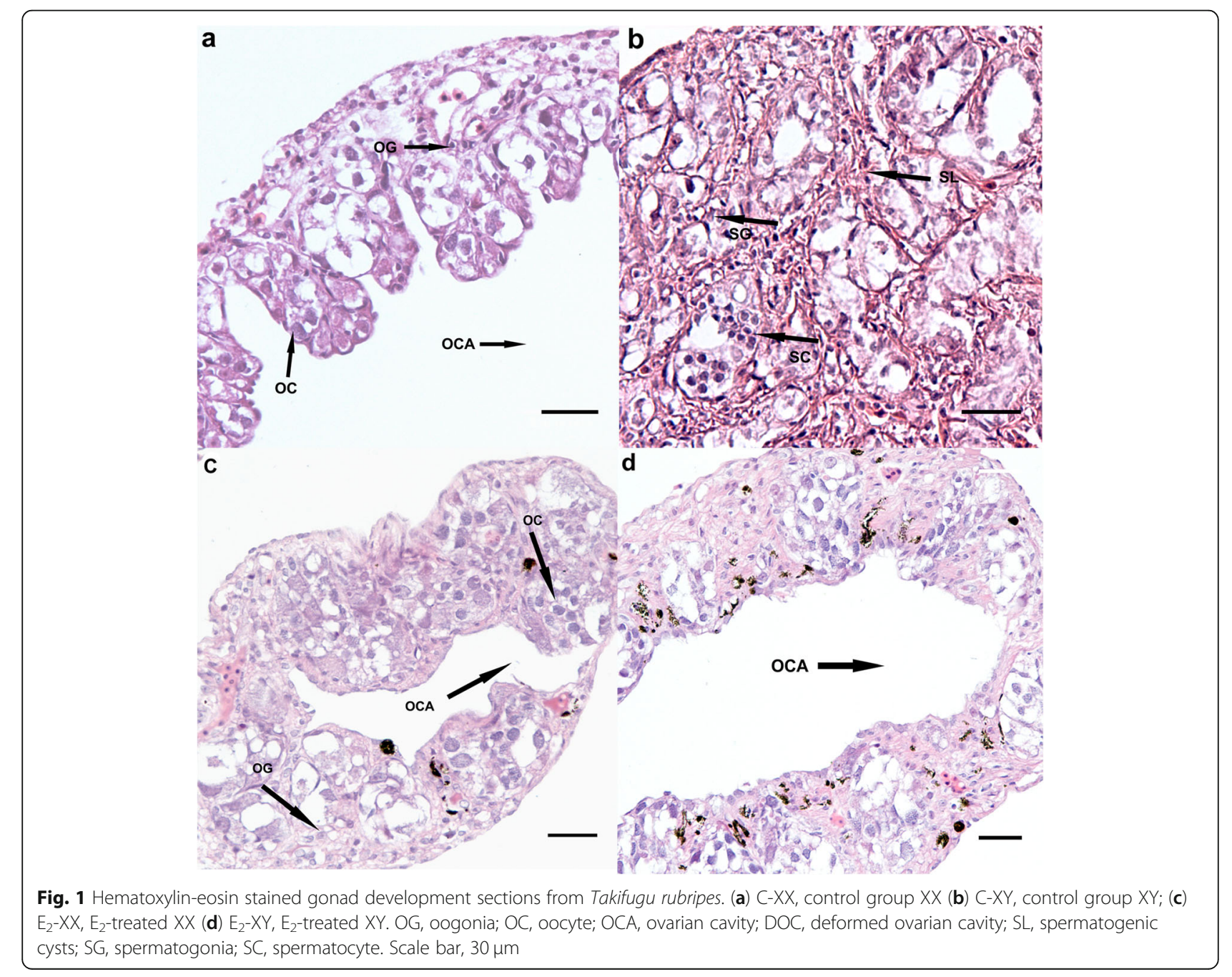


and 44,804,906 (E-XY_3) clean reads were obtained from each library, respectively (Table 1 ).

As shown in Figs. S1, only four DEGs were identified in the $\mathrm{C}-\mathrm{XY}$ versus (vs) $\mathrm{C}-\mathrm{XX}$ comparison, of which three DEG were up-regulated and one was downregulated, such as aryl hydrocarbon receptor interacting protein-like 1 (aipl1), serine protease hepsin-like, and nucleoprotein TPR-like (Table 2). There were 411 DEGs between $\mathrm{E}_{2}$-treated (E-XX and $\left.\mathrm{E}-\mathrm{XY}\right)$ and Control (C-XX and C-XY) in total (Fig. 2). In the E-XX vs C-XX comparison, 301 DEGs were identified, of which 85 were up-regulated (Fig. 3 a). These included gonadotropin-releasing hormone 1 (gnrh1), cytochrome P450 aromatase (cyp19a1b), progesterone receptor (pgr), solute carrier family 6 (slc6a20) and cytochrome P450 1A1-like (cyp1a1). There were 216 downregulated DEGs in this comparison, which included prolactin $(p r l)$, thyroid stimulating hormone (tshb), somatolactin-like $(s l)$, glycoprotein hormones $(c g a)$ and pro-opiomelanocortin-like (pomc) (Table 2). Moreover, 224 DEGs were identified in the E-XY vs C-XY comparison, of which 52 were up-regulated (Fig. $3 b$ ), such as vitellogenin-2-like (vtg2), pgr, gnrh1, cyp19a1b, zona pellucida sperm-binding protein 4-like $(z p 3)$ and cyp1a1. 172 down-regulated DEGs were observed in this comparison. These included potassium channel (kcnk18), WD40 repeat-containing protein ( $w d 40)$, basic helix-loop-helix family (bhlhe41) and forkhead box protein O1-a (foxoa) (Table 2). In the E-XX vs E$\mathrm{XY}$ comparison, only 3 up-regulated DEGs were identified, including hetc-domain, protein MAATS1-like (maats1), and uncharacterized LOC105419364 (Table $2)$. In the E-XY vs C-XX comparison, 96 were upregulated, such as cyp19a1b, cypla1 and pgr. 184 down-regulated DEGs were observed, such as bhlhe41, WD40 and kcnk18 (Table S1).

\section{GO enrichment analysis of DEGs}

In the $\mathrm{C}-\mathrm{XY}$ vs $\mathrm{C}-\mathrm{XX}, \mathrm{E}-\mathrm{XX}$ vs $\mathrm{C}-\mathrm{XX}$ and $\mathrm{E}-\mathrm{XY}$ vs $\mathrm{C}$ $\mathrm{XY}$ comparisons, genes were mainly enriched in biological processes, followed by molecular function and cellular component $\mathrm{GO}$ terms (Fig. S2, 4). In the $\mathrm{C}-\mathrm{XY}$ vs $\mathrm{C}-\mathrm{XX}$ comparison, the DEGs were mainly significantly enriched in microtubule-based movement and movement of cell or subcellular component in the biological process category. In the molecular function category, they were enriched in serine-type exopeptidase activity and exopeptidase activity (Fig. S2). In the E-XX vs C-XX comparison, DEGs were mainly enriched in response to oxygen-containing compound, response to drug and proteolysis, for biological process, in hormone activity, sequence-specific DNA binding and serine-type peptidase activity, for molecular function, and in calcium ion binding, myosin complex and actin cytoskeleton, for cellular component. The up-regulated genes were mainly clustered in proteolysis, for the biological process category, extracellular region, for the cellular component category, and hormone activity, for the molecular function category. The down-regulated genes were mainly clustered in cell cycle arrest, for the biological process category, myosin complex, for the cellular component category, and protein kinase regulator activity, for the molecular function category (Fig. 4a). In the E-XY vs C$\mathrm{XY}$ comparison, response to oxygen-containing compound, response to chemical and response to extracellular stimulus were highly represented for the biological process category. Integral component of plasma membrane, intrinsic component of plasma membrane and plasma membrane part were highly represented for the cellular component category. Sequence-specific DNA binding, heme binding and tetrapyrrole binding were highly represented for the molecular function category. The up-regulated genes were mainly clustered in

Table 1 Summary statistics of the transcriptome sequencing and mapping in Takifugu rubripes

\begin{tabular}{llllll}
\hline Sample & Raw data & Clean_reads & Total_map & Unique_map & Multi_map \\
\hline C-XX_1 & $44,523,690$ & $43,622,952$ & $40,982,945(93.95 \%)$ & $39,573,936(90.72 \%)$ & $1,409,009(3.23 \%)$ \\
C-XX_2 & $44,523,690$ & $44,436,616$ & $41,718,759(93.88 \%)$ & $40,266,124(90.61 \%)$ & $1,452,635(3.27 \%)$ \\
C-XX_3 & $66,606,798$ & $42,850,608$ & $40,099,291(93.58 \%)$ & $38,741,203(90.41 \%)$ & $1,358,088(3.17 \%)$ \\
C-XY_1 & $43,978,518$ & $42,851,086$ & $39,724,413(92.7 \%)$ & $38,336,011(89.46 \%)$ & $1,388,402(3.24 \%)$ \\
C-XY_2 & $46,201,180$ & $45,072,134$ & $42,198,181(93.62 \%)$ & $40,661,639(90.21 \%)$ & $1,536,542(3.41 \%)$ \\
C-XY_3 & $46,409,586$ & $45,005,800$ & $42,144,064(93.64 \%)$ & $40,678,707(90.39 \%)$ & $1,465,357(3.26 \%)$ \\
E-XX_1 & $44,537,526$ & $43,442,122$ & $40,708,228(93.71 \%)$ & $39,264,335(90.38 \%)$ & $1,443,893(3.32 \%)$ \\
E-XX_2 & $40,345,586$ & $39,629,744$ & $37,253,090(94.0 \%)$ & $35,927,359(90.66 \%)$ & $1,325,731(3.35 \%)$ \\
E-XX_3 & $49,202,476$ & $48,253,210$ & $45,656,235(94.62 \%)$ & $44,078,863(91.35 \%)$ & $1,577,372(3.27 \%)$ \\
E-XY_1 & $47,529,109$ & $46,193,034$ & $43,403,167(93.96 \%)$ & $41,703,371(90.28 \%)$ & $1,699,796(3.68 \%)$ \\
E-XY_2 & $43,506,024$ & $42,700,218$ & $40,001,299(93.68 \%)$ & $38,698,894(90.63 \%)$ & $1,302,405(3.05 \%)$ \\
E-XY_3 & $45,728,118$ & $44,804,906$ & $42,008,134(93.76 \%)$ & $40,598,629(90.61 \%)$ & $1,409,505(3.15 \%)$ \\
\hline
\end{tabular}


Table 2 Selection of some of DEGs identified in C-XYvsC-XX, E-XXvsC-XX, E-XYvsC-XY, and E-XX vs E-XY

\begin{tabular}{|c|c|c|c|c|}
\hline \multirow{2}{*}{$\frac{\text { Gene name }}{(C-X Y v s C-X X)}$} & \multirow[t]{2}{*}{ log2 Fold change } & \multicolumn{2}{|c|}{ Average FPKM } & \multirow[t]{2}{*}{ Description } \\
\hline & & C-XX & C-XY & \\
\hline aip/1 & 1.38 & 2.7 & 7.01 & aryl hydrocarbon receptor interacting protein-like 1 \\
\hline LOC101065721 & 1.11 & 2.15 & 4.64 & serine protease hepsin-like \\
\hline LOC101063021 & 1.15 & 29.49 & 62.37 & nucleoprotein TPR-like \\
\hline$(\mathrm{E}-\mathrm{XX} \mathbf{\mathrm { N }} \mathrm{C}-\mathrm{XX})$ & & $E-X X$ & $C-X X$ & \\
\hline arntl & 1.37 & 18.73 & 7.26 & aryl hydrocarbon receptor nuclear translocator-like \\
\hline bhlhe41 & -2.06 & 11 & 45.96 & basic helix-loop-helix family member e41 \\
\hline cga & -7.19 & 0.267 & 38.54 & glycoprotein hormones alpha polypeptide \\
\hline cipc & -1.96 & 15.72 & 44.78 & CLOCK-interacting pacemaker-like \\
\hline ciart & -1.33 & 6.45 & 16.25 & circadian-associated transcriptional repressor-like \\
\hline cyp19b & 2.59 & 81.97 & 13.67 & cytochrome P450 aromatase \\
\hline cypla1 & 2.25 & 6.89 & 1.45 & cytochrome P450 1A1-like \\
\hline gnrh1 & 3.45 & 12.83 & 1.168 & gonadotropin-releasing hormone 1 \\
\hline per1 & -1.63 & 9.27 & 28.66 & period circadian clock 1 \\
\hline per3 & -1.31 & 10.26 & 25.51 & period circadian clock 3 \\
\hline pgr & 2.55 & 1.35 & 0.23 & progesterone receptor \\
\hline$p r l$ & -11.94 & 0.02 & 86.17 & prolactin \\
\hline pomc & -7.17 & 5.77 & 832.18 & pro-opiomelanocortin-like \\
\hline poulf1 & -4.66 & 0.053 & 1.37 & POU class 1 homeobox 1 \\
\hline tshb & -11.07 & 0 & 52.91 & thyroid stimulating hormone beta \\
\hline sl & -9.9 & 0.04 & 38.65 & somatolactin-like \\
\hline slc6a20 & 2.12 & 8.82 & 2.03 & solute carrier family 6 member 20 \\
\hline (E-XYvsC-XY) & & $E-X Y$ & C-XY & \\
\hline bhlhe41 & -2.25 & 10.48 & 49.91 & basic helix-loop-helix family member e41 \\
\hline cyp19b & 2.82 & 90.7 & 12.84 & cytochrome P450 aromatase \\
\hline cypla1 & 1.84 & 5.66 & 1.58 & cytochrome P450 1A1-like \\
\hline gnrh1 & 3.35 & 17.5 & 1.72 & gonadotropin-releasing hormone 1 \\
\hline kcnk18 & -3.05 & 0.51 & 4.2 & potassium channel two pore domain subfamily member 18 \\
\hline per3 & -1.35 & 10.59 & 27.02 & period circadian clock 3 \\
\hline pgr & 3.81 & 1.51 & 0.11 & progesterone receptor \\
\hline vtg2 & 6.54 & 0.72 & 0.01 & vitellogenin-2-like \\
\hline Wd40 & -2.89 & 3.19 & 23.56 & WD40 repeat-containing protein SMU1-like \\
\hline zp4 & 2.11 & 3.46 & 0.8 & zona pellucida sperm-binding protein 4-like \\
\hline (E-XXvsE-XY) & & $\mathrm{E}-\mathrm{XX}$ & $\mathrm{E}-\mathrm{XY}$ & \\
\hline hetc & 8.77 & 2.78 & 0 & HETC (ubiquitin-transferase) \\
\hline maats1 & 1.18 & 5.6 & 2.41 & protein MAATS1-like \\
\hline LOC105419364 & 6.56 & 1.88 & 0 & uncharacterized LOC105419364 \\
\hline
\end{tabular}

response to extracellular stimulus and response to nutrient levels, in the biological process category, integral component of plasma membrane, for the cellular component category, and sequence-specific DNA binding, for the molecular function category. The down-regulated genes were clustered in lipid transport and lipid localization in the biological process category (Fig. 4b).

\section{KEGG enrichment analysis of DEGs}

The most enriched KEGG pathways in the E-XX vs C$\mathrm{XX}$ comparison were neuroactive ligand-receptor interaction, arachidonic acid metabolism, cytokine-cytokine receptor interaction and the calcium signaling pathway. The KEGG pathways most enriched by down-regulated DEGs were neuroactive ligand-receptor interaction, 


\section{a}

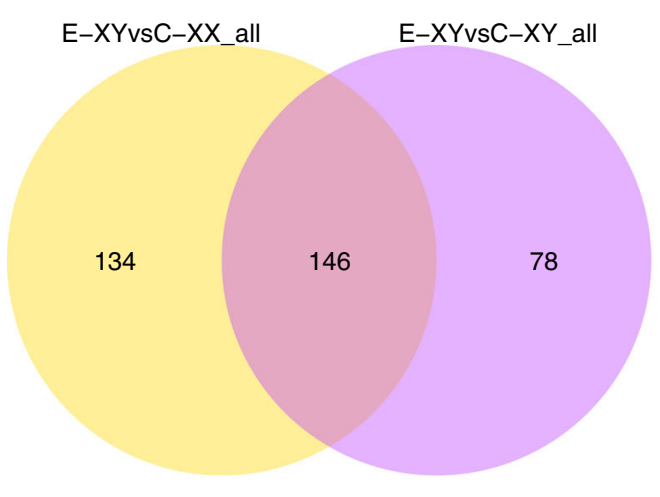

b

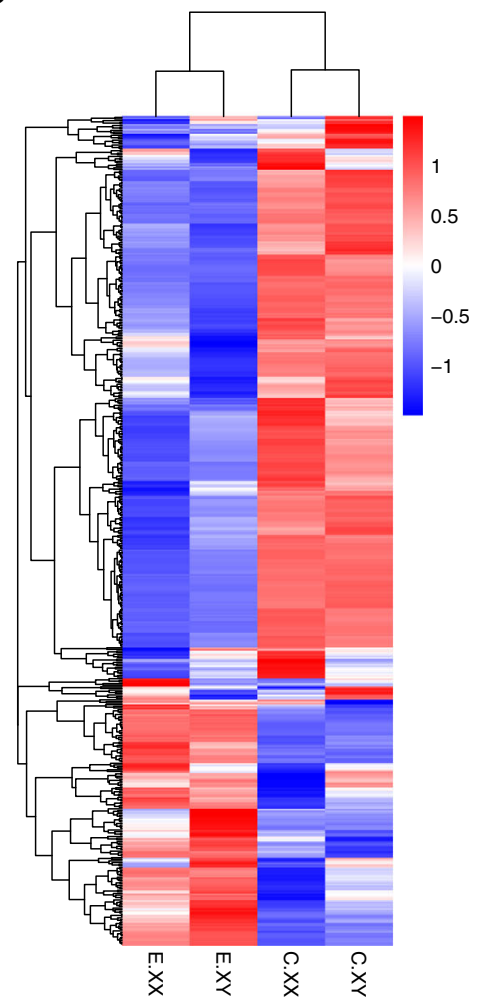

Fig. 2 The DEGs observed between the control and $E_{2}$-treated groups, based on FPKM units. Venn diagram (a) and Heat map (b). C-XX, control group $X X ; C-X Y$, control group $X Y ; E_{2}-X X, E_{2}$-treated $X X ; E_{2}-X Y, E_{2}$-treated $X Y$

steroid hormone biosynthesis, retinol metabolism, calcium signaling pathway and GnRH signaling pathway. Eight pathways, which included neuroactive ligandreceptor interaction, notch signaling pathway, cytokinecytokine receptor interaction, PPAR signaling pathway, steroid biosynthesis, calcium signaling pathway, metabolism of xenobiotics by cytochrome P450 and GnRH signaling pathway, were the most enriched by upregulated DEGs (Fig. 5a). In the E-XY vs C-XY comparison, the most enriched KEGG pathways were tyrosine metabolism, phenylalanine metabolism, arachidonic acid metabolism and linoleic acid metabolism. The pathways
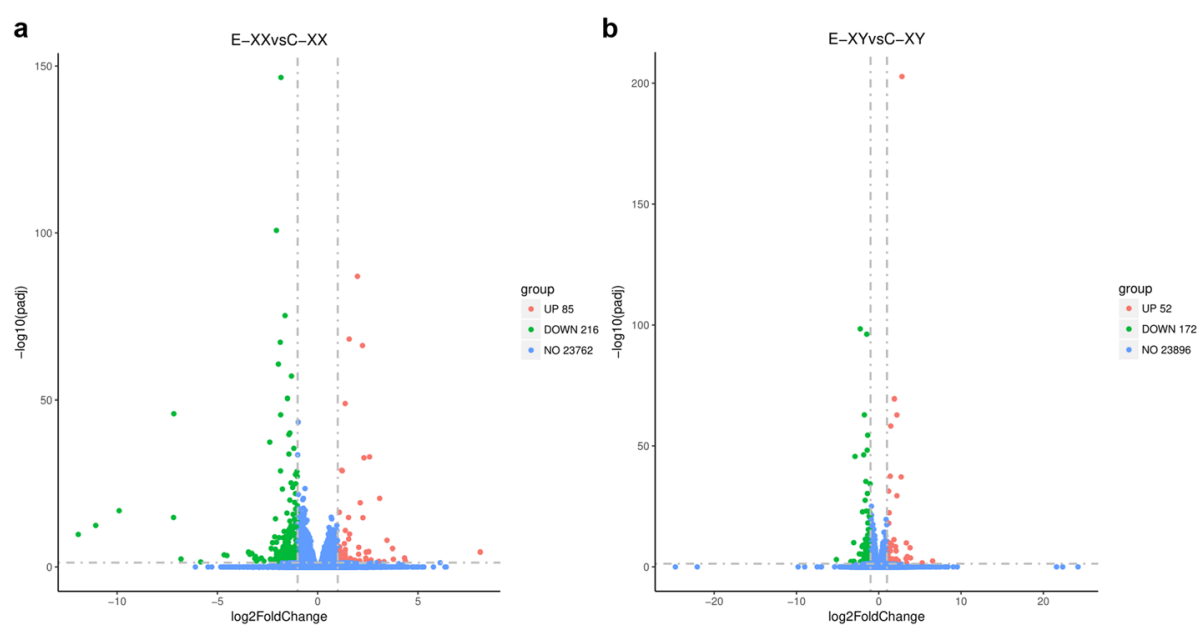

Fig. 3 Volcano plot of differences in gene expression between control and $E_{2}$-treated groups. (a) E-XX vs C-XX, (b) E-XY vs C-XY; Up-regulated genes (red), and down-regulated genes (green) 

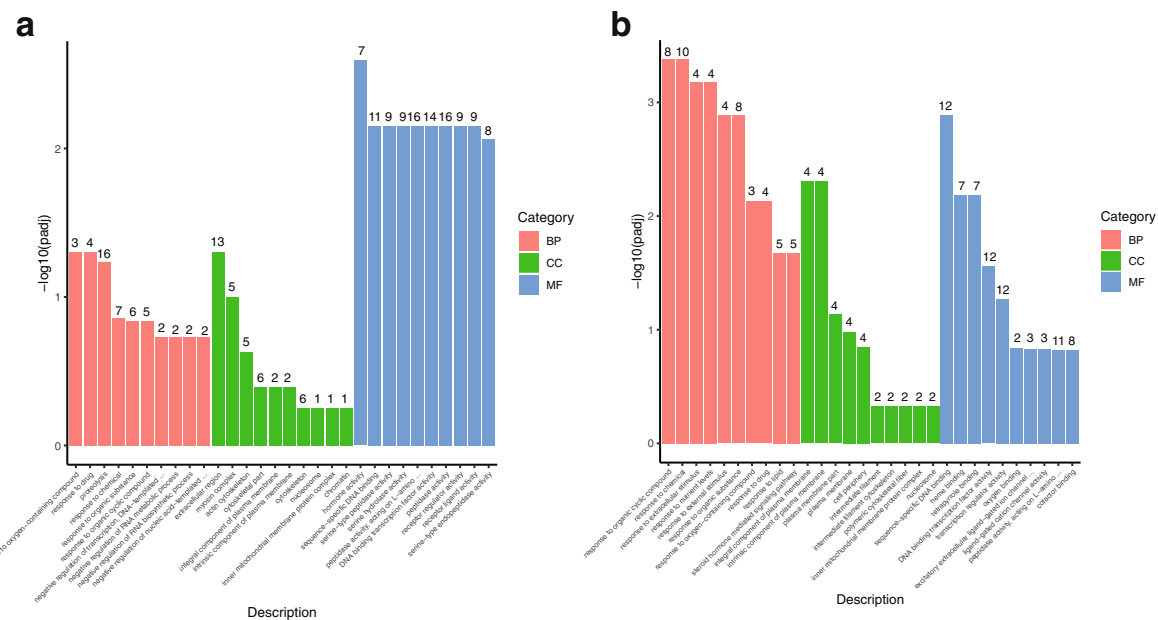

Fig. 4 Gene ontology (GO) enrichment of DEGs for E-XX vs C-XX (a), and E-XY vs C-XY(b)

most enriched by down-regulated DEGs were steroid hormone biosynthesis, retinol metabolism, PPAR signaling pathway, carbon metabolism, metabolism of xenobiotics by cytochrome $\mathrm{P} 450$, calcium signaling pathway and neuroactive ligand-receptor interaction. The tyrosine metabolism, phenylalanine metabolism, arachidonic acid metabolism, linoleic acid metabolism, alpha-linolenic acid metabolism, steroid biosynthesis, histidine metabolism, metabolism of xenobiotics by cytochrome P450, tryptophan metabolism and calcium signaling pathways were those most enriched by upregulated DEGs (Fig. 5b).

\section{qPCR}

The qPCR analysis was used to verify RNA-Seq results (Fig. 6). In the control group, no significant difference in mRNA level of gnrh1, cyp1a1 and cyp19a1b was found between the $\mathrm{XY}$ and $\mathrm{XX}$ groups $(p>0.05)$. In the $\mathrm{E}_{2}$ treatment group, the expression of gnrh1, cyp1a1 and cyp19a1a, in XX and XY larvae, was significantly higher than in the control group $(p<0.05)$. The level of cyp19a1b in the $\mathrm{E}_{2}$-treated $\mathrm{XY}$ group was significantly higher than in the $E_{2}$-treated XX group. In the control group, no significant difference was observed in the expression level of prph, per1b, per3, cipc and ciart, between XY and XX larvae, whilst the level of nart1 was significantly lower in XY larvae than in XX larvae $(p<$ 0.05). The expression levels of bh1be, nr1d2, per1b, per3, cipc and ciart, in $\mathrm{E}_{2}$-treated larvae brains, were significantly lower than in the control group $(p<0.05)$, whilst the expression levels of arntlla and cryl were significantly higher than in the control group $(p<0.05)$.

\section{Discussion}

To date, the use of $E_{2}$ for gender control has been reported in at least 56 bony fish genera from 24 families.
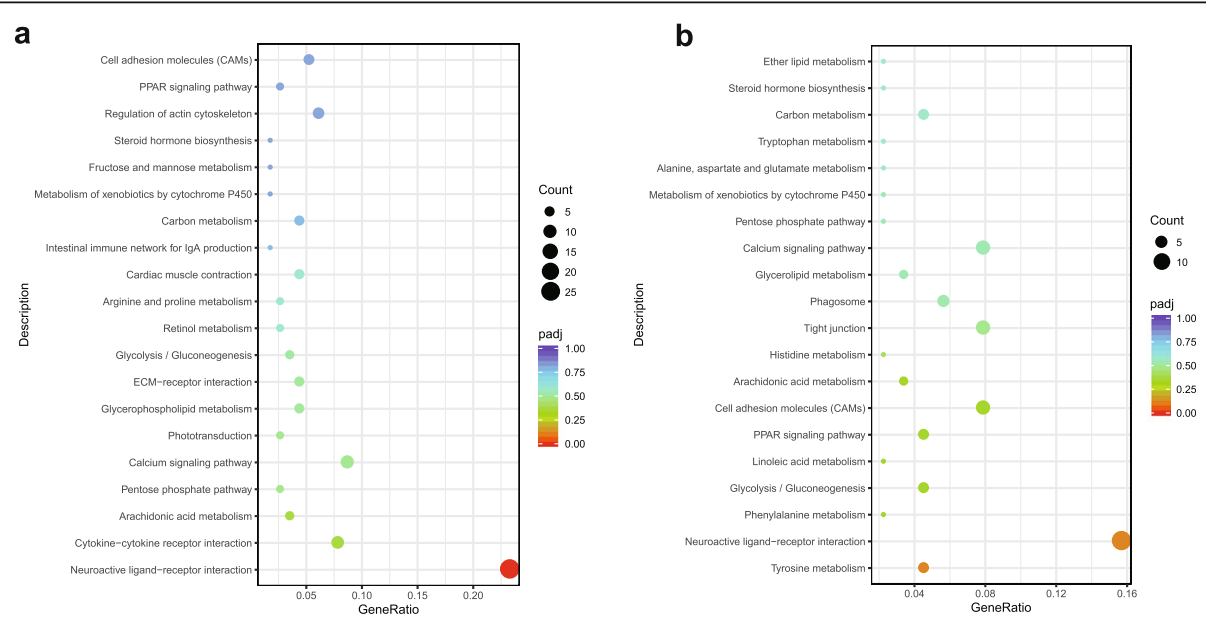

Fig. 5 KEGG enrichment analyses of DEGs for E-XX vs C-XX (a), and E-XY vs C-XY (b) 

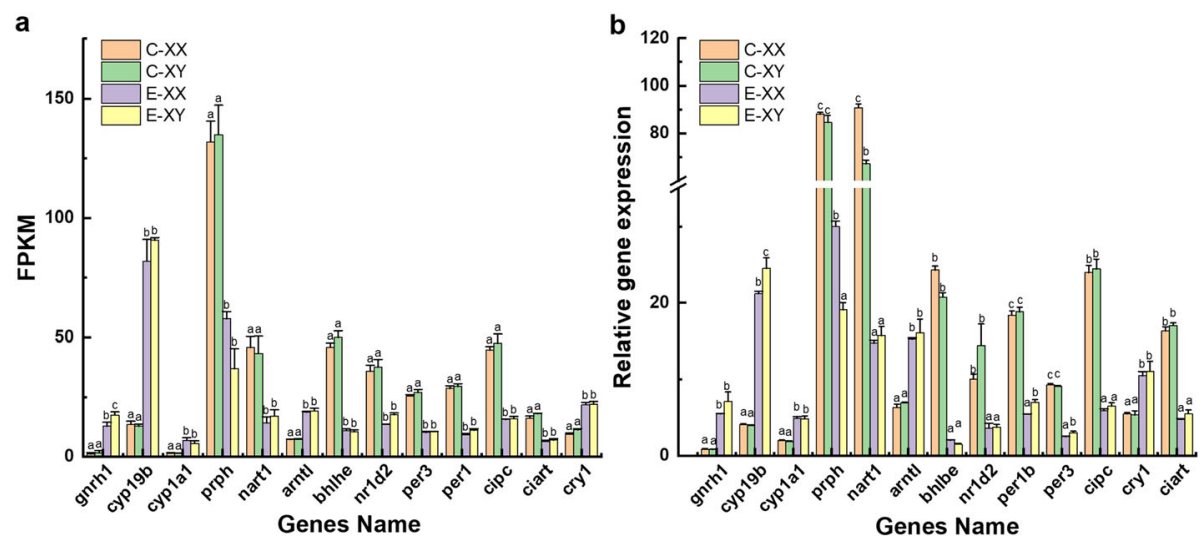

Fig. 6 The expression level of gnrh1, cyp19a1b, cyp1a1, prph, nart1, arntl1a, bhlbe, nr1d2, per1b, per3, cipc, cry1 and ciart in the T. rubripes brain after $\mathrm{E}_{2}$ treatment. FPKM (reads per kb per million reads) of obtained by RNA-seq (a). The relative expression levels of genes obtained by qPCR (b). C, Control group; $E_{2}, E_{2}$-treated group. Each value represents the mean $\pm S D$ of three measurements. One-way ANOVA ( $p$-value $<0.05$ ) was used for analysis

These fish include rainbow trout (Oncorhynchus mykiss), fighting fish (Betta splendens) and tilapia (Oreochromis niloticus) [44-49]. In T. rubripes, previous studies have also found that treatment with $\mathrm{E}_{2}$, during early sex differentiation, can induce feminization $[8,48,49]$. In our previous study, by $\mathrm{E}_{2}$-treatment $(100 \mu \mathrm{g} / \mathrm{L} / \mathrm{time}, 2 \mathrm{~h} /$ time, 1 time/day, from 25 dah to 55 dah), feminization of XY T. rubripes was induced, and the results of the transcriptomic analysis of gonads showed that a large number of DEGs and pathways involved in the process of feminization of XY T. rubripes [22]. For example, the expression of cyp19a1a, foxl2, gsdf, dmrt1, cyp11a1, cyp17a1, hsd3b1, hsd17b1 and cyp11c1 changed dramatically in the gonad when torafugu were treated with $E_{2}$. In this study, we analyzed the brain transcriptome in order to better clarify the effects of estrogen on gonadal differentiation. The number of DEGs (eight DEGs at 80 dah) identified in the brain in the C-XX vs C-XY comparison was fewer than that identified at 30 dah (250 DEGs) and 40 dah (499 DEGs), in our previous study [43]. This could be attributed to the use of different differentiation stages of the torafugu that were employed in the two transcriptomic analyses. In addition, more DEGs were identified in the brain in both the $\mathrm{E}$-XX vs $\mathrm{C}$-XX comparison (514 DEGs) and E-XY vs C-XY comparison (362 DEGs). This suggests that the exogenous $\mathrm{E}_{2}$ triggered significant alteration of gene expression profiles in the brains of both $\mathrm{XX}$ and $\mathrm{XY}$ torafugu.

Various effects of exposure to $E_{2}$ have been observed in teleosts. These effects include changes in brain development, endocrine regulation, gonadal development, growth, bone development, rhythm, feeding behavior and absorption, which are closely related to fish brain modulation [50, 51]. Aromatase (CYP19A1) catalyzes the biosynthesis of estrogens from androgens. In contrast to most mammalian species, which possess a single
Cyp19 gene, most teleosts possess duplicated copies of cyp19a1, namely cyp19a1a and cyp19a1b [52, 53]. The cyp19a1a gene is predominantly expressed in the ovary, while cyp $19 a 1 b$ is predominantly expressed in the brain and is critical for $E_{2}$ biosynthesis [53, 54]. After $E_{2}$ treatment, the expression level of cyp19a1b was up-regulated in the both $\mathrm{XX}$ and $\mathrm{XY}$ torafugu brain, which indicates that the $E_{2}$ synthesized in the brain can be influenced by circulating $\mathrm{E}_{2}$ levels. The up-regulation of cyp 19a1b gene expression by estrogenic compound administration also observed in zebrafish $[55,56]$. In silico analyses of the torafugu cyp19a1b promoter have identified putative ERE binding sites (5'-TGACC-3', 5'-GGTCAG-3'), similar to those identified in stickleback and medaka [57]. Thus, ERE may be necessary for $E_{2}$-regulated cyp $19 a 1 b$ expression in torafugu.

The GnRH neurons are the principal output neurons from the hypothalamus and control reproduction [58]. Three paralogous forms of these neurons exist, termed GnRH1, GnRH2 and GnRH3 [59]. Pulsatile secretion of GnRH1 is essential for reproduction in all vertebrates. It induces follicle-stimulating hormone (FSH) and luteinizing hormone (LH) secretion in the pituitary, which triggers gonadal steroidogenesis [60]. In $T$. rubripes, the levels of gnrh1 expression in the GnRH signaling pathway were up-regulated in the $\mathrm{XX}$ and $\mathrm{XY}$ brain. The use of $E_{2}$ has also been shown to induce gnrh1 up-regulation in other vertebrates [58-60]. In vivo experiments in mice showed that $\mathrm{E}_{2}$ rapidly acts as a hormone-activated transcription complex, to increase GnRH1 neuronal activity via ER [61]. However, ERs have not been identified as DEGs between our control and $E_{2}$ treatment groups. This may be due to the limitation of the transcriptomic analysis being performed at a coarse anatomical scale (such as the whole brain). Thus, we cannot exclude the possibility that the up-regulation of 
gnrh1, by exogenous estrogen, occurs via ER in the torafugu brain.

In addition, the progesterone receptor ( $p g r)$ was upregulated in the both $\mathrm{XX}$ and $\mathrm{XY}$ torafugu brain after $\mathrm{E}_{2}$ treatment. Like other members of the steroid receptor superfamily, progesterone receptors are vertebrate intracellular, ligand-inducible transcription factors [62] that are activated in the absence of their ligands by alterations in phosphorylation status [63]. Estradiol exerts positive or negative feedback on the hypothalamicpituitary system [64-66]. Bashour et al., (2012) found that progesterone can act directly on GnRH neurons, through Pgr [66], and McCartney et al., (2009, 2010) found that the progesterone-sensitive mechanism is influenced by gonadal steroids $[67,68]$. In rats, a previous study indicated that Pgr is a downstream mediator of the estradiol/ER $\alpha$ action in kisspeptin neurons $[69,70]$. Therefore, $p g r$ may be involved in the mediation of $\mathrm{E}_{2}$ induced gnrh1 expression in the torafugu brain. In this study, we also found $v \operatorname{tg} 2$ and $z p 4$ were expressed in brain of XY torafugu by transcriptome sequencing. Vitellogenin is synthesized in the liver of all oviparous taxa and transported in the blood to the ovary, which is the common yolk precursor protein [71]. The zona pellucida $(\mathrm{ZP})$ is an extracellular glycoprotein matrix that surrounds all mammalian oocytes [72]. In teleost species, ZP genes are expressed either in liver under regulation of estrogen or in ovary [72]. However, why there is an extopic expression of those tow genes in torafugu brain and how they involved in the process of sex differentiation needs to study in the future.

Our previous study also found that the body lengths of larvae in $E_{2}$-treated groups were less than those in the control group and the survival rate of larvae was only $17 \%$. It proved that $E_{2}$ significantly inhibits growth, survival and gonad development in torafugu larvae [22]. The results were similiar to data from both tilapia [73] and rainbow trout [74], in addition to results from another study on torafugu [48]. However, the mechanisms that underlie the effects are not clear. In mammals, it has been demonstrated that there is a close interdependence among the factors that regulate growth and reproduction, which involve the interactions between multiple growth peptides and estrogens, with their receptors $[75,76]$. In our transcriptome data, somatotropin (st), thyroid stimulating hormone beta (tshb), somatolactin-like $(s l)$, prolactin $(p r l)$ and pou1f1 (pit-1), which related development and growth of teletost [7791] were down-regulated in the $\mathrm{XX}$ and $\mathrm{XY} T$. rubripes brain after $E_{2}$ treatment. Therefore, $E_{2}$ may downregulate those genes, by which inhibiting fugu growth and gonad development. Circadian rhythm is essential for living organisms to regulate a wide array of behavior and physiology, such as sleep, activity, reproduction, feeding and endocrine functions [92]. It exists in most life forms, from unicellular bacteria to higher organisms [93]. Although the basic regulatory mechanisms and functions follow the same general design, the conservation of expression of genes involved in the circadian rhythm, throughout the kingdom, is limited [94]. Here, transcriptomic and analysis showed that the core regulators of gene expression in the $\mathrm{XX}$ and $\mathrm{XY}$ brain, involved in the circadian rhythm, were altered by $E_{2}$ treatment in both sexes in torafugu. For example, arntlla and cry1 were up-regulated and bhlbe, nr1d2, per1, per3, cipc and ciart were down-regulated after $\mathrm{E}_{2}$ treatment. Recently, there has been increasing evidence to suggest that estrogens can alter circadian clock gene expression in mammals [95-100]. Therefore, the significant alteration of the expression levels of circadian clock genes indicates that estrogen may also interfere with the biological clock in torafugu.

The DEGs observed between the $\mathrm{E}_{2}$-treated and control groups in both sexes were significantly enriched in KEGG pathways such as neuroactive ligand-receptor interaction, calcium signaling pathway and cell adhesion molecules (CAMs). The neuroactive ligand-receptor interaction pathway comprised all ligands and receptors in the cell membrane for signal transduction [100]. Cell adhesion molecules are proteins located on the cell surface and are required for the assembly and interconnection of various cellular functions, maintenance of tissue integration and wound healing [101, 102]. Our results suggest that exogenous stimulating hormones can interfere with signal transduction. In the E-XX group, the cytokine-cytokine receptor interaction pathway was the most significantly affected, when compared with E-XY. Cytokines can act in the CNS as immunoregulators and neuromodulators during health and disease [103, 104]. During cytokinecytokine interactions, convergence of signaling pathways and divergence of the cytokine signal to activate other cytokine systems are involved in synergistic activities [104]. In the olive flounder, all 11 pathways were enriched in the brains of $E_{2}$-treated phenotypic females, for example, circadian rhythm, circadian entrainment, dopaminergic synapse, calcium signaling, glutamatergic synapse, long-term depression, and taste transduction pathways, etc. [29]. The circadian rhythm, calcium signaling and glutamatergic synapse pathways were also enriched in our study. These results suggest that cell adhesion, transport, circadian rhythm and the calcium signaling pathway may be affected by exposure to $E_{2}$ in teleosts.

In conclusion, by using transcriptomic sequencing of $\mathrm{XX}$ and $\mathrm{XY}$ brains of torafugu larvae to show that many genes and pathways were altered by $\mathrm{E}_{2}$ exposure. The genes and pathways identified here will help to elucidate the genetic basis behind the $E_{2}$-induced feminization process. The data also open the possibility of 
investigating networks in the brain-pituitary-gonadal axis in torafugu.

\section{Materials and methods \\ Animals}

Twenty days after hatching (dah), torafugu larvae of $6.40 \pm 0.1 \mathrm{~mm}$ body length were purchased from Dalian Fugu Aquatic Product Co., Ltd., Dalian, China.

\section{Treatment of $T$. rubripes larvae}

Based on previous studies, treated fugu with $100 \mu \mathrm{g} / \mathrm{L}$ $17 \beta$-estradiol $\left(\mathrm{E}_{2}\right) \quad(2 \mathrm{~h}$ once a day $)$ can induced feminization $[22,105]$, none of the treated $\mathrm{XY}$ fugu reverted to testes [105]. In the present study, after a short period of acclimatization (five days), 5700 larvae were randomly divided into two groups (control and $\mathrm{E}_{2}$-treated groups) and three replicates were created for each group (950 larvae/tank (approximately $100 \mathrm{~L}$ )). The oxygen level was maintained $>8 \mathrm{mg} / \mathrm{L}$, the $\mathrm{pH}$ was maintained at $7.9-$ 8.1, and salinity of $33 \mathrm{ppt}$ and a temperature of approximately $20.5-21.5^{\circ} \mathrm{C}$. $\mathrm{E}_{2}$ powder of $\geq 99 \%$ purity (Sigma, St. Louis, MO, USA) was dissolved in $95 \%$ ethanol to form a solution for the experimental treatment. The $\mathrm{E}_{2}$ administration method was the same as described in our previous study [22]. The experiments were carried out at $\sim 21.0^{\circ} \mathrm{C}$, under a natural photoperiod. Approximately $200 \mathrm{~L}$ water was changed after the two-hour $\mathrm{E}_{2}$ exposure.

\section{Tissue sampling}

At the end of the experiment ( 55 days after treatment (dat)), larvae were anesthetized in ice water. Gonads to be used for histological analysis were dissected and fixed in $4 \%$ paraformaldehyde for $24 \mathrm{~h}$. They were then stored in $70 \%$ ethanol. Sampling of brains was performed using 90 torafugu from each treatment (30 larvae per tank). Brains were stored individually in RNAlater reagent (Thermo Fisher Scientific, Baltics, USA), in a $1.5 \mathrm{~mL}$ plastic tube on ice. They were then snap-frozen in liquid nitrogen and stored at $-80^{\circ} \mathrm{C}$ until RNA extraction and sequencing. For genetic sex verification, a piece of fin tissue sample was stored in a $1.5 \mathrm{ml}$ tube containing $100 \%$ alcohol in a freezer at $-20^{\circ} \mathrm{C}$ individually.

\section{Histological analysis, genetic gender verification and RNA preparation}

Histological analyses were conducted as described previously [19]. After histological observation, in order to identify $E_{2}$-induced feminized torafugu, genomic DNA from the paraffin-block tissue was extracted in accordance with the manufacturer's instructions (TIANamp FFPE DNA kit, Tiangen, China). For RNA-seq and quantitative (qPCR), genetic sex identification was also performed before RNA extraction. DNA was extracted from the fin tissues using the TIANamp Marine Animals

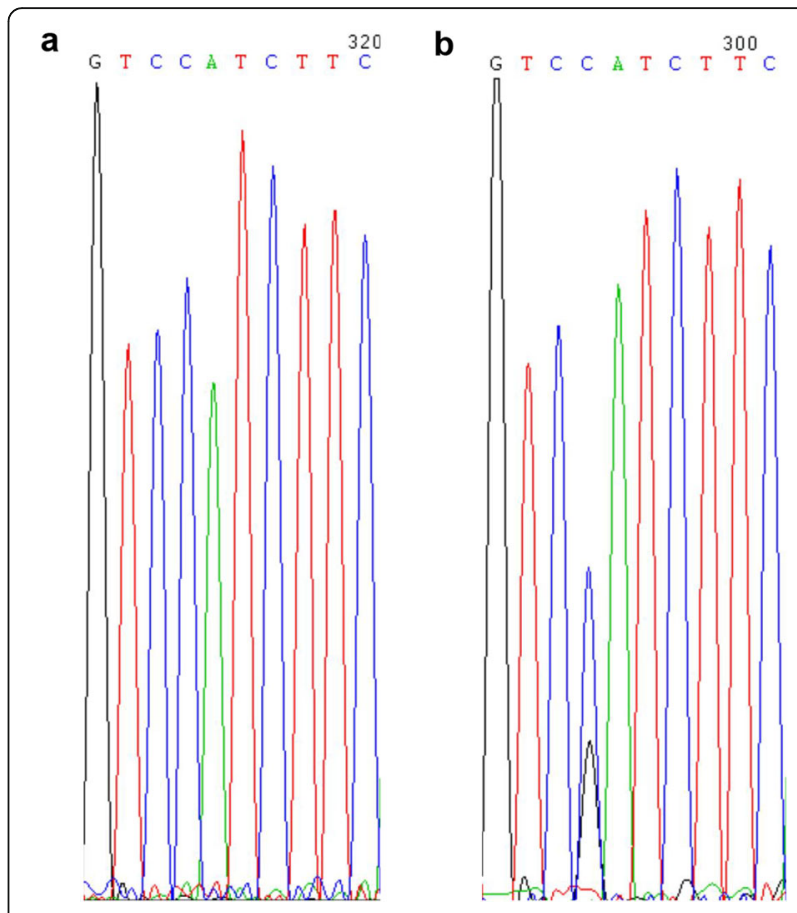

Fig. 7 Sequence traces of amhr2 from a female (left) and a male (right) fugu. The male is heterozygous at the non-synonymous SNP site that converts His384 codon into Asp384 codon

DNA kit (Tiangen, Beijing, China). Genetic gender verification for each larva was performed before RNA extraction from brains. The gender was verified using an SNP on amhr2 gene exon 9, through PCR amplified a region containing exon 9 and flanking introns using primers SD3exon8F (5'-CAGATGCACACAAACCAC CT-3') and SD3exon10R (5'-TCCCAGTGTTGCG GTATGTA-3'). Previous studies have demonstrated there is a perfect concordance between the SNP genotype and phenotypic sex $[15,18,19]$. As shown in (Fig. 7), the genotype of males was $\mathrm{C} / \mathrm{G}(\mathrm{XY})$ and that of females was $\mathrm{C} / \mathrm{C}(\mathrm{XX})$. After sex verification, total RNA from brain sample from each individual was prepared in accordance with a previously described protocol [19].

\section{RNA-Seq}

Total RNA concentration was measured with a NanoDrop ND-1000 spectrophotometer (Thermo Scientific, Wilmington, DE, USA) and RNA integrity was assessed with an Agilent 2100 Bioanalyzer (Agilent Technologies, Santa Clara, CA, USA). Libraries were prepared as follows; for each replicate, a pool of $6 \mu \mathrm{g}$ of RNA from genetic XX or XY torafugu $(1 \mu \mathrm{g}$ of purified brain RNA from each individual, six individuals were mixed together) was regarded as a single sample and $1 \mu \mathrm{g}$ of RNA per sample was used as input material. Twelve sequencing libraries, which included the control XX (C-XX_1, C-XX_2, C-XX_3), control XY (C-XY_1, C-XY_2, C- 
$\left.X Y \_3\right), E_{2}$-treated $X X$ (E-XX_1, E-XX_2, E-XX_3), and $E_{2}$-treated XY (E-XY_1, E-XY_2, E-XY_3), were generated using a NEBNext Ultra RNA Library Prep kit for Illumina (NEB, Ipswich, MA, USA) [41]. The products were purified using an AMPure XP system (Beckman Coulter, Beverly, USA) to obtain a region of approximately 250 to $300 \mathrm{bp}$. The library preparations were conducted as previously described [19].

The reference genome and gene model annotation file were downloaded directly from NCBI (ftp://ftp.ncbi.nlm. nih.gov/genomes/all/GCF_000180615.1_FUGU5) and Hisat2 v2.0.5 was used for the alignment analysis of clean data from each library. The most common method, fragments of kilobase per exon model per million reads mapped (FPKM) was used to calculate gene expression levels. Differential expression analysis for the control or $\mathrm{E}_{2}$-treamented groups was conducted using the DESeq2 $\mathrm{R}$ package. The $p$-values were adjusted in

Table 3 Primers used for qPCR of $\beta$-actin and sex-biased genes

\begin{tabular}{|c|c|c|c|}
\hline Name & Primer & Sequence $\left(5^{\prime}-3^{\prime}\right)$ & Length (bp) \\
\hline \multirow[t]{2}{*}{$\beta$-actin } & Forward & CAGATGTGGATCAGCAAGCA & 245 \\
\hline & Reverse & GCTGAAGTTGTTGGGCATTI & \\
\hline \multirow[t]{2}{*}{ gnrhl } & Forward & GCTGGTCGGGAGTCTGATGT & 155 \\
\hline & Reverse & AACCCAGAAGAGCGGAGGA & \\
\hline \multirow[t]{2}{*}{ cyp19b } & Forward & AACAAGTACGGCAGCCTGG & 153 \\
\hline & Reverse & TCCCTCCATCCCGATACACT & \\
\hline \multirow[t]{2}{*}{ cypla1 } & Forward & ATGGCACCGAGGTCAACAA & 119 \\
\hline & Reverse & CAGGATTGCCAGGAAGAGGTA & \\
\hline \multirow[t]{2}{*}{ prph } & Forward & AAGCCATAGGAAAGGAGAGGG & 137 \\
\hline & Reverse & GCGGAAGGCAATCAGGTTA & \\
\hline \multirow[t]{2}{*}{ nart1 } & Forward & TTCCCACAATAACCAGCATCA & 147 \\
\hline & Reverse & CACGCTTACACTITCAGCAACA & \\
\hline \multirow[t]{2}{*}{ arntlia } & Forward & TCCTGTTTGTGGTCGGTTGT & 181 \\
\hline & Reverse & CTCTCTCGTGGGGCTGTATCT & \\
\hline \multirow[t]{2}{*}{ bhlbe } & Forward & GCGACGGCAAAGATAAAGATAC & 200 \\
\hline & Reverse & CTGTCCCACGCTGCTTATTC & \\
\hline \multirow[t]{2}{*}{$\operatorname{nrld} 2$} & Forward & CGCCCACATCAACAAGGA & 187 \\
\hline & Reverse & ATGTGCGTAGGTGGGAGTGT & \\
\hline \multirow[t]{2}{*}{ perib } & Forward & CACCCTCAACGCACTCAAA & 175 \\
\hline & Reverse & GTCGGTGTIITTCAGGGTGTA & \\
\hline \multirow[t]{2}{*}{ per3 } & Forward & ACAATGGTTCCAGCGGTTAT & 109 \\
\hline & Reverse & TGCGAGTCCTCCCACAGA & \\
\hline \multirow[t]{2}{*}{ cipc } & Forward & ACAGGGTCAAAGGAAGGGTG & 105 \\
\hline & Reverse & GTTGGTGATGCTGATGCTTGT & \\
\hline \multirow[t]{2}{*}{ cry 1} & Forward & AGGCGGGTGTAGAGGTCATT & 110 \\
\hline & Reverse & GGTCTGGAAACGCTTGTAGGT & \\
\hline \multirow[t]{2}{*}{ ciart } & Forward & CGCTCCCTCCAAGATTCCT & 145 \\
\hline & Reverse & TGAGACGAGGGCACTTGTAGAG & \\
\hline
\end{tabular}

accordance with methods that have been reported previously [42]. The threshold for significant differential expression was a $p$-value of 0.05 and $\log 2$ (fold-change) of 1 [106]. Subsequently, gene ontology (GO) and Kyoto Encyclopedia of Genes and Genomes (KEGG) enrichment analyses were performed to categorize differentially expressed genes (DEGs). The GO terms and pathways with a corrected $p$-value of less than 0.05 were considered significantly enriched.

\section{qPCR verification}

The gnrh1, cyp19a1b, cyp1a1, prph, nart1, arntl1a, bhlbe, nr1dd2, per1b, per3, cipc, cry1 and ciart genes were randomly selected for RNA-seq validation by qPCR, using an Applied Biosystems 7900 HT Real-Time PCR system, as described previously [18]. The reference gene used for the $\mathrm{qPCR}$ analysis was $\beta$-actin. Primers for the reference gene and other genes selected for validation were designed using the Primer Premier 5.0 program (Table 3). The relative expression of genes was calculated using the $2^{-\Delta \Delta C T}$ method. Data are expressed as the mean \pm SEM. Statistical significance analysis between the treatment and control groups was conducted using one-way ANOVA ( $p$-value $<0.05)$ in the IBM SPSS software.

\section{Supplementary Information}

The online version contains supplementary material available at https://doi. org/10.1186/s12864-021-08158-0.

Additional file 1.

Additional file 2.

Additional file 3.

\section{Acknowledgements}

We are deeply grateful to Xin Cui, and Xiaoyi Luo and other students from our research team, who were involved in the rearing process and sampling of specimens.

\section{Authors' contributions}

SX dealt with the experimental materials and wrote the manuscript. YH designed the research. JJ, LW performed the experiments, interpreted the results, and analyzed the data. $X Y, L Q$, and $L Y$ revised the paper. All authors have read and approved the manuscript.

\section{Funding}

This research was supported by Youth Program of National Natural Science Foundation of China (31902347), General Project of Education Department of Liaoning Province (JL201904), the Projects for Dalian Youth Star of Science and Technology (2019RQ130). Scientific, Technological and Innovation Program of Dalian (2018J12SN069), and R\&D Program of Liaoning Province (2019JH2/10200015).

\section{Availability of data and materials}

The data sets supporting the results of this article are available at the SRA database of NCBI (https://www.ncbi.nlm.nih.gov/) under project accession number PRJNA760675. 


\section{Declarations}

\section{Ethics approval and consent to participate}

All experiments including torafugu procedures described here were approved by the lab animal protection regulations and guidelines of the Key Laboratory of Environment Controlled Aquaculture, Ministry of Education at Dalian Ocean University, Dalian, China. All methods were carried out in accordance with relevant Liaoning province and China's guidelines and regulations. All methods of this study also adhere to the ARRIVE Guidelines for reporting animal research.

\section{Consent for publication}

Not applicable.

\section{Competing interests}

The authors declare that they have no conflict of interest.

\section{Author details}

'College of Life Sciences, Liaoning Normal University, Dalian 116029, Liaoning, China. ${ }^{2}$ Key Laboratory of Environment Controlled Aquaculture (Dalian Ocean University) Ministry of Education, Dalian 116023, China. ${ }^{3}$ College of Fisheries and Life Science, Dalian Ocean University, Dalian 116023, Liaoning, China. ${ }^{4}$ College of Marine Science and Environment Engineering, Dalian Ocean University, Dalian 116023, Liaoning, China.

\section{Received: 6 September 2021 Accepted: 8 November 2021} Published online: 24 November 2021

\section{References}

1. Hughes IA. Minireview: sex differentiation. Endocrinology. 2001;142(8):32817. https://doi.org/10.1210/endo.142.8.8406.

2. Nagahama Y, Chakraborty T, Paul-Prasanth B, Ohta K, Nakamura M. Sex determination, gonadal sex differentiation, and plasticity in vertebrate species. Physiol Rev. 2021;101(3):1237-308. https://doi.org/10.1152/physrev. 00044.2019.

3. Devlin $\mathrm{RH}$, Nagahama Y. Sex determination and sex differentiation in fish: an overview of genetic, physiological, and environmental influences. Aquaculture. 2002;208(3-4):191-364. https://doi.org/10.1016/S0044-8486(02 )00057-1.

4. Brown EE, Baumann $\mathrm{H}$, Conover DO. Temperature and photoperiod effects on sex determination in a fish. J Exp Mar Biol Ecol. 2014;461(12):39-43. https://doi.org/10.1016/j.jembe.2014.07.009.

5. Hayasaka O, Takeuchi Y, Shiozaki K, Anraku K, Kotani T. Green light irradiation during sex differentiation induces female-to-male sex reversal in the medaka Oryzias latipes. Sci Rep. 2019;9(1):1-8. https://doi.org/10.1038/ s41598-019-38908-w.

6. Li M, Sun L, Wang D. Roles of estrogens in fish sexual plasticity and sex differentiation. Gen Comp Endocrinol. 2019;277(6):9-16. https://doi.org/10.1 016/j.ygcen.2018.11.015.

7. Kobayashi H, Iwamatsu T. Sex reversal in the medaka Oryzias latipes by brief exposure of early embryos to estradiol-17ß. Zool Sci. 2005;22(10):1163-7. https://doi.org/10.2108/zsj.22.1163.

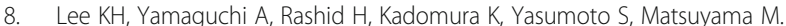
Estradiol-17 $\beta$ treatment induces intersexual gonadal development in the pufferfish. Zool Sci. 2009;26(9):639-45. https://doi.org/10.2108/zsj.26.639.

9. Zhang Y, Zhang S, Lu H, Zhang L, Zhang W. Genes encoding aromatases in teleosts: evolution and expression regulation. Gen Comp Endocrinol. 2014; 205(9):151-8. https://doi.org/10.1016/j.ygcen.2014.05.008.

10. Li M-H, Yang H-H, Li M-R, Sun Y-L, Jiang X-L, Xie Q-P, et al. Antagonistic roles of Dmrt1 and Fox 12 in sex differentiation via estrogen production in tilapia as demonstrated by TALENs. Endocrinology. 2013;154(12):4814-25. https://doi.org/10.1210/en.2013-1451.

11. Lau ESW, Zhang Z, Qin M, Ge W. Knockout of zebrafish ovarian aromatase gene (cyp19a1a) by TALEN and CRISPR/Cas9 leads to all-male offspring due to failed ovarian differentiation. Sci Rep. 2016;6(1):1-14. https://doi.org/10.1 038/srep37357.

12. Zhang X-B, Li M-R, Ma H, Liu X-Y, Shi H-J, Li M-H, et al. Mutation of fox/2 or cyp19a1a results in female to male sex reversal in XX Nile tilapia. Endocrinology. 2017;158(8):2634-47. https://doi.org/10.1210/en.2017-00127.
13. Yamamoto TO. Progeny of artificially induced sex-reversals of male genotype $(X Y)$ in the medaka (Oryzias latipes) with special reference to $Y Y$ male. Genetics. 1955;40(3):406-19. https://doi.org/10.1093/genetics/40.3.406.

14. Liu H, Guan B, Xu J, Hou C, Tian H, Chen H. Genetic manipulation of sex ratio for the large-scale breeding of $Y Y$ super-male and $X Y$ all-male yellow catfish (Pelteobagrus fulvidraco (Richardson)). Mar Biotechnol. 2013;15(3):3218. https://doi.org/10.1007/s10126-012-9487-7.

15. Sun Y-L, Jiang D-N, Zeng S, Hu C-J, Ye K, Yang C, et al. Screening and characterization of sex-linked DNA markers and marker-assisted selection in the Nile tilapia (Oreochromis niloticus). Aquaculture. 2014;433:19-27. https:// doi.org/10.1016/j.aquaculture.2014.05.035.

16. Schill DJ, Heindel JA, Campbell MR, Meyer KA, Mamer ER. Production of a YY male brook trout broodstock for potential eradication of undesired brook trout populations. N A J Aquacult. 2016;78(1):72-83. https://doi.org/1 $0.1080 / 15222055.2015 .1100149$

17. Aparicio S, Chapman J, Stupka E, Putnam N, Chia JM, Dehal P, et al. Whole genome shotgun assembly and analysis of the genome of Fugu rubripes. Science. 2002;297(5585):1301-10.

18. Kamiya T, Kai W, Tasumi S, Oka A, Matsunaga T, Mizuno N, et al. A transspecies missense SNP in Amhr2 is associated with sex determination in the tiger pufferfish, Takifugu rubripes (fugu). PLoS Genet. 2012;8(7):e1002798. https://doi.org/10.1371/journal.pgen.1002798.

19. Yamaguchi A, Lee KH, Fujimoto H, Kadomura K, Yasumoto S, Matsuyama M. Expression of the DMRT gene and its roles in early gonadal development of the Japanese pufferfish Takifugu rubripes. Comp Biochem Phys D. 2006;1(1): 59-68. https://doi.org/10.1016/j.cbd.2005.08.003.

20. Rashid H, Kitano H, Lee KH, Nii S, Shigematsu T, Kadomura K, et al. Fugu (Takifugu rubripes) sexual differentiation: CYP19 regulation and aromatase inhibitor induced testicular development. Sex Dev. 2007;1(5):311-22. https:// doi.org/10.1159/000108935.

21. Yan H-W, Shen X-F, Cui X, Wu Y-M, Wang L-S, Zhang L, et al. Identification of genes involved in gonadal sex differentiation and the dimorphic expression pattern in Takifugu rubripes gonad at the early stage of sex differentiation. Fish Physiol and Bioche. 2018;44(5):1275-90. https://doi.org/1 0.1007/s10695-018-0519-8.

22. Yan H-W, Shen X-F, Jiang J-M, Zhang L, Yuan Z, Wu Y-M, et al. Gene expression of Takifugu rubripes gonads during Al or MT-induced masculinization and E2-induced feminization [J]. Endocrinology. 2021; 162(10):bqab068.

23. Burgoyne PS, Thornhill AR, Boudrean SK, Darling SM, Bishop CE, Evans EP. The genetic basis of XX-XY differences present before gonadal sex differentiation in the mouse. Philos Trans R Soc Lond B Biol Sci. 1995; 350(1333):253-61. https://doi.org/10.1098/rstb.1995.0159.

24. Dewing P, Shi T, Horvath S, Vilain E. Sexually dimorphic gene expression in mouse brain precedes gonadal differentiation. Mol Brain Res. 2003;118(1-2): 82-90. https://doi.org/10.1016/S0169-328X(03)00339-5.

25. Lowe R, Gemma C, Rakyan VK, Holland ML. Sexually dimorphic gene expression emerges with embryonic genome activation and is dynamic throughout development. BMC Genomics. 2015;16(1):1-13. https://doi.org/1 0.1186/s12864-015-1506-4.

26. Dennis C. Brain development: the most important sexual organ. Nature 2004;427(6973):390-3. https://doi.org/10.1038/427390a.

27. Davies W, Wilkinson LS. It is not all hormones: alternative explanations for sexual differentiation of the brain. Brain Res. 2006;1126(1):36-45. https://doi. org/10.1016/j.brainres.2006.09.105.

28. Lee SLJ, Horsfield JA, Black MA, Rutherford K, Gemmell NJ. Identification of sex differences in zebrafish (Danio rerio) brains during early sexual differentiation and masculinization using 17a-methyltestoterone. Biol Reprod. 2018;99(2):446-60. https://doi.org/10.1093/biolre/iox175.

29. Zou Y-X, Wu Z-H, Fan Z-F, Liang D-D, Wang L-J, Song Z-C, et al. Analyses of mRNA-seq and miRNA-seq of the brain reveal the sex differences of gene expression and regulation before and during gonadal differentiation in $17 \beta-$ estradiol or 17a-methyltestosterone-induced olive flounder (Paralichthys olivaceus). Mol Reprod Dev. 2020;87(1):78-90. https://doi.org/10.1002/ $\operatorname{mrd} .23303$.

30. Lu J-G, Zheng M, Zheng J-J, Liu J, Liu Y-Z, Peng L-N, et al. Transcriptomic analyses reveal novel genes with sexually dimorphic expression in yellow catfish (Pelteobagrus fulvidraco) brain. Mar Biotechnol. 2015;17(8):613-23. https://doi.org/10.1007/s10126-015-9650-z

31. Sreenivasan $R$, Cai M, Bartfai R, Wang X, Christoffels A, Orban L. Transcriptomic analyses reveal novel genes with sexually dimorphic 
expression in the zebrafish gonad and brain. PLoS One. 2008;3(3):e1791. https://doi.org/10.1371/journal.pone.0001791.

32. Chen X, Agate RJ, Itoh Y, Arnold AP. Sexually dimorphic expression of trkB, a Z-linked gene, in early posthatch zebra finch brain. PNAS. 2005;102(21): 7730-5. https://doi.org/10.1073/pnas.0408350102.

33. Agate RJ, Choe M, Arnold AP. Sex differences in structure and expression of the sex chromosome genes CHDIZ and CHDIW in zebra finches. Mol Biol Evol. 2004;21(2):384-96. https://doi.org/10.1093/molbev/msh027.

34. Xu J, Burgoyne PS, Arnold AP. Sex differences in sex chromosome gene expression in mouse brain. Hum Mol Genet. 2002;1 1(12):1409-19. https:// doi.org/10.1093/hmg/11.12.1409.

35. Xu J, Deng X, Watkins R, Disteche CM. Sex-specific differences in expression of histone demethylases Utx and Uty in mouse brain and neurons. J Neurosci. 2008:28(17):4521-7. https://doi.org/10.1523/JNEUROSCI.5382-07.2008.

36. Maehiro S, Takeuchi A, Yamashita J, Hiraki T, Kawabata Y, Nakasone K, et al. Sexually dimorphic expression of the sex chromosome-linked genes cntfa and pdlim3a in the medaka brain. Biochem Biophys Res Commun. 2014; 445(1):113-9. https://doi.org/10.1016/j.bbrc.2014.01.131.

37. Senthilkumaran B, Sudhakumari CC, Mamta SK, Raghuveer K, Swapna I, Murugananthkumar R. "Brain sex differentiation" in teleosts: emerging concepts with potential biomarkers. Gen Comp Endocrinol. 2015;220(9):3340. https://doi.org/10.1016/j.ygcen.2015.06.003

38. Gahr M. Male Japanese quails with female brains do not show male sexual behaviors. PNAS. 2003;100(13):7959-64. https://doi.org/10.1073/pnas.133 5934100.

39. Munday PL, Buston PM, Warner RR. Diversity and fexibility of sex change strategies in animals. Trends Ecol Evol. 2006;21(2):89-95. https://doi.org/10.1 016/j.tree.2005.10.020.

40. Todd EV, Ortega-Recalde O, Liu H, Lamm MS, Rutherford KM, Cross H, et al. Stress, novel sex genes, and epigenetic reprogramming orchestrate socially controlled sex change. Sci Adv. 2019;5(7):eaaw7006.

41. Zhang Z, Lau SW, Zhang L, Ge W. Disruption of zebrafsh follicle-stimulating hormone receptor (fshr) but not luteinizing hormone receptor (lhcgr) gene by TALEN leads to failed follicle activation in females followed by sexual reversal to males. Endocrinology. 2015;156(10):3747-62.

42. Zhang Z, Zhu B, Ge W. Genetic analysis of zebrafsh gonadotropin (FSH and $L H)$ functions by TALEN-mediated gene disruption. Mol Endocrinol. 2015; 29(1):76-98. https://doi.org/10.1210/me.2014-1256.

43. Shen X-F, Yan H-W, Zhang L, Yuan Z, Liu W-L, Wu Y-M, et al. Transcriptomic analyses reveal novel genes with sexually dimorphic expression in Takifugu rubripes brain during gonadal sex differentiation. Genes Genom. 2020;42(1): 425-39. https://doi.org/10.1007/s13258-019-00914-7.

44. Chevassus B, Devaux A, Chourrout D, Jalabert B. Production of YY rainbow trout males by self-fertilization of induced hermaphrodites. J Hered. 1988; 79(2):89-92. https://doi.org/10.1093/oxfordjournals.jhered.a1 10478.

45. Varadaraj K, Pandian TJ. First report on production of supermale tilapia by integrating endocrine sex reversal with gynogenetic technique. Curr Sci India. 1989;58(4):434-41.

46. Kavumpurath $\mathrm{S}$, Pandian TJ. Effects of induced triploidy on aggressive display in the fighting fish, Betta splendens Regan. Aquac Res. 1992;23(3): 281-90. https://doi.org/10.1111/j.1365-2109.1992.tb00771.x.

47. Piferrer F. Endocrine sex control strategies for the feminization of teleost fish. Aquaculture. 2001;197(1-4):229-81. https://doi.org/10.1016/50044-84 86(01)00589-0.

48. Ren $Y$, Zhou $Q$, Liu $Y-X$, Wang $Y-F$, Wang $Q-L$, Jiang $X-F$, et al. Effects of estradiol-17 $\beta$ on survival, growth performance, gonadal structure and sex ratio of the tiger puffer, Takifugu rubripes (Temminck and Schlegel, 1850), fingerlings. Aquac Res. 2018;49(4):1638-46. https://doi.org/1 0.1111 /are.13619.

49. Yaron Z, Levavi-Sivan B. Endocrine regulation of fish reproduction []]. Encyclopedia of fish physiology: from genome to environment. 2011;2: 1500-8. https://doi.org/10.1016/B978-0-12-374553-8.00058-7.

50. Diotel N, Vaillant C, Gabbero C, Mironov S, Fostier A, Gueguen MM, et al. Effects of estradiol in adult neurogenesis and brain repair in zebrafish. Horm Beha. 2013;63(2):193-207. https://doi.org/10.1016/j.yhbeh.2012.04.003.

51. Le Page Y, Menuet A, Kah O, Pakdel F. Characterization of a cis-acting element involved in cell-specific expression of the zebrafish brain aromatase gene. Mol Reprod Dev. 2008;75(10):1549-57. https://doi.org/10.1002/mrd.2 0892.

52. Guiguen Y, Fostier A, Piferrer F, Chang CF. Ovarian aromatase and estrogens: a pivotal role for gonadal sex differentiation and sex change in fish. Gen Comp Endocr. 2010;165(3):352-66. https://doi.org/10.1016/j.ygcen.2 009.03.002.

53. Roselli CE, Resko JA. Aromatase activity in the rat brain: hormonal regulation and sex differences. J Ste Biochem. 1993;44(4-6):499-508. https://doi.org/1 0.1016/0960-0760(93)90254-T.

54. Konkle ATM, McCarthy MM. Developmental time course of estradiol, testosterone, and dihydrotestosterone levels in discrete regions of male and female rat brain. Endocrinology. 2011;152(1):223-35. https://doi.org/10.1210/ en.2010-0607.

55. Tong SK, Chung B. Analysis of zebrafish cyp 19 promoters. J Ste Biochem. 2003;86(3-5):381-6. https://doi.org/10.1016/S0960-0760(03)00347-9.

56. Böhne A, Heule C, Boileau N, Salzburger W. Expression and sequence evolution of aromatase cyp19a1 and other sexual development genes in east African cichlid fishes. Mol Biol Evol. 2013;30(10):2268-85. https://doi. org/10.1093/molbev/mst124.

57. Menuet A, Pellegrini E, Brion F, Gueguen MM, Kah O. Expression and estrogen-dependent regulation of the zebrafish brain aromatase gene. J Comp Neurol. 2005;485(4):304-20. https://doi.org/10.1002/cne.20497.

58. Adams C, Stroberg W, DeFazio RA, Schnell S, Moenter SM. Gonadotropinreleasing hormone $(\mathrm{GnRH})$ neuron excitability is regulated by estradiol feedback and kisspeptin. J Neurosci. 2018;38(5):124-1263. https://doi.org/1 0.1523/JNEUROSCI.2988-17.2017.

59. Fernald RD, White RB. Gonadotropin-releasing hormone genes: phylogeny, structure, and functions. Front Neuroendocrinol. 1999;20(3):224-40. https:// doi.org/10.1006/frne.1999.0181.

60. Herbison AE. A simple model of estrous cycle negative and positive feedback regulation of GnRH secretion. Front Neuroendocrinol. 2020;57(4): 100837. https://doi.org/10.1016/j.yfrne.2020.100837.

61. Temple JL, Laing E, Sunder A, Wray S. Direct action of estradiol on gonadotropin-releasing hormone-1 neuronal activity via a transcriptiondependent mechanism. J Neurosci. 2004;24(28):6326-33. https://doi.org/10.1 523/JNEUROSCI.1006-04.2004.

62. Wiegand SJ, Terasawa BWE. Persistent estrus and blockade of progesteroneinduced $\mathrm{LH}$ release follows lesions which do not damage the suprachiasmatic nucleus. Endocrinology. 1978;102(5):1645-8. https://doi. org/10.1210/endo-102-5-1645.

63. Weigel NL, Moore NL. Steroid receptor phosphorylation: a key modulator of multiple receptor functions. Mol Endocrinol. 2007:21(5):2311-9. https://doi. org/10.1210/me.2007-0101.

64. Lasley BL, Wang C-F, Yen S-S. The effects of estrogen and progesterone on the functional capacity of the gonadotrophs. J Clin Endocrinol Metab. 1975; 41(9):820-6. https://doi.org/10.1210/jcem-41-5-820.

65. Turgeon JL, Waring DW. Modification of luteinizing hormone secretion by activators of Ca2p/phospholipid-dependent protein kinase. Endocrinology. 1986;118(5):2053-8. https://doi.org/10.1210/endo-118-5-2053.

66. Bashour NM, WrayS. Progesterone directly and rapidly inhibits GnRH neuronal activity via progesterone receptor membrane component 1. Endocrinology. 2012;153(9):4457-69. https://doi.org/10.1210/en.2012-1122.

67. McCartney CR, Prendergast KA, Blank SK, Helm KD, Sandhya C, Marshall JC. Maturation of luteinizing hormone (gonadotropin-releasing hormone) secretion across puberty: evidence for altered regulation in obese peripubertal girls. J Clin Enocr Metab. 2009;94(1):56-66. https://doi.org/1 0.1210/jc.2008-1252.

68. McCartney CR. Maturation of sleep-wake gonadotrophin-releasing hormone secretion across puberty in girls: potential mechanisms and relevance to the pathogenesis of polycystic ovary syndrome. J Neuroendocrinol. 2010;22(7): 701-9. https://doi.org/10.1111/j.1365-2826.2010.02029.x.

69. Gal A, Lin PC, Cacioppo JA, Hannon PR, Ko CM. Loss of fertility in the absence of progesterone receptor expression in kisspeptin neurons of female mice. PLoS One. 2016;11(7):e0159534. https://doi.org/10.1371/journal. pone. 0159534

70. Waring DW, Turgeon JL. A pathway for luteinizing hormone releasinghormone self-potentiation: cross-talk with the progesterone receptor. Endocrinology. 1992;130(6):3275-82. https://doi.org/10.1210/ endo.130.6.1317780.

71. Polzonetti-Magni AM, Mosconi G, Soverchia L, Kikuyama S, Carnevali O. Multihormonal control of vitellogenesis in lower vertebrates. Int Rev Cytol. 2004;239(Supplement C):1-46.

72. Arukwe A, Kullman SW, Berg K, Goksøyr A, Hinton DE. Molecular cloning of rainbow trout (Oncorhynchus mykiss) eggshell zona radiata protein complementary DNA: mRNA expression in 17ß-estradiol-and nonylphenol- 
treated fish. Comp Bio Phy B. 2002;132(2):315-26. https://doi.org/10.1016/S1 096-4959(02)00009-X.

73. Davis LK, Hiramatsu N, Hiramatsu K, Reading BJ, Matsubara T, Sullivan HA, et al. Induction of three vitellogenins by 17 beta-estradiol with concurrent inhibition of the growth hormone-insulin-like growth factor 1 axis in a euryhaline teleost, the tilapia (Oreochromis mossambicus). Biol Reprod. 2007: 77(4):614-25. https://doi.org/10.1095/biolreprod.107.060947.

74. Hanson AM, Kittilson JD, McCormick SD, Sheridan MA. Effects of $17 \beta$ estradiol, 4-nonylphenol, and $\beta$-sitosterol on the growth hormone-insulinlike growth factor system and seawater adaptation of rainbow trout (Oncorhynchus mykiss). Aquaculture. 2012;362:241-7. https://doi.org/10.1016/ j.aquaculture.2010.09.015.

75. Meinhardt UJ, Ho KKY. Modulation of growth hormone action by sex steroids. Clin Endocrinol. 2006;65(4):413-22. https://doi.org/10.1111/j.1365-22 65.2006.02676.x

76. Leung KC, Johannsson G, Leong GM, Ho KKY. Estrogen regulation of growth hormone action. Endocr Rev. 2004;25(5):693-721. https://doi.org/10.1210/ er.2003-0035.

77. Kasper M, Schnidar H, Neill GW, Hanneder M, Klingler S, Blaas L, et al. Selective modulation of hedgehog/GL/ target gene expression by epidermal growth factor signaling in human keratinocytes. Mol Cell Biol. 2006;26(16): 6283-98. https://doi.org/10.1128/MCB.02317-05.

78. Liu H, Todd EV, Lokman PM, Lamm MS, Godwin JR, Gemmell NJ. Sexual plasticity: a fishy tale. Mol Reprod Dev. 2017;84(2):171-94. https://doi.org/1 0.1002/mrd.22691.

79. Peterson BC, Bosworth BG, Bilodeau AL. Differential gene expression of IGF-I, IGF-II, and toll-like receptors 3 and 5 during embryogenesis in hybrid (channelxblue) and channel catfish. Comp Biochem Phys A. 2005;141(1):427. https://doi.org/10.1016/j.cbpb.2005.03.009.

80. Berishvili G, D'Cotta H, Baroiller JF, Segner H, Reinecke M. Differential expression of IGF-I mRNA and peptide in the male and female gonad during early development of a bony fish, the tilapia Oreochromis niloticus. Gen Comp Endcor. 2006;146(3):204-10. https://doi.org/10.1016/j.ygcen.2 005.11.008.

81. Nader MR, Miura T, Ando N, Miura C, Yamauchi K. Recombinant human insulin-like growth factor I stimulates all stages of 11-ketotestoster-oneinduced spermatogenesis in the Japanese eel, Anguilla japonica, in vitro. Biol Reprod. 1999:61(10):944-7. https://doi.org/10.1095/ biolreprod61.4.944.

82. Weber GM, Sullivan CV. Effects of insulin-like growth factor-I on in vitro final oocyte maturation and ovarian steroidogenesis in striped bass. Biol Reprod. 2000;63(4):1049-57. https://doi.org/10.1095/biolreprod63.4.1049.

83. Silva JRV, Figueiredo JR, Van den Hurk R. Involvement of growth hormone $(\mathrm{GH})$ and insulin-like growth factor (IGF) system in ovarian folliculogenesis. Theriogenology. 2009;71(8):1193-208. https://doi.org/10.1016/j. theriogenology.2008.12.015.

84. Minakhina S, Bansal S, Zhang A, Brotherton M, Wondisford FE. A direct comparison of thyroid hormone receptor protein levels in mice provides unexpected insights into thyroid hormone action. Thyroid. 2020;30(8):1193204. https://doi.org/10.1089/thy.2019.0763.

85. Han Y-S, Liao I-C, Tzeng W-N, Yu J. Cloning of the CDNA for thyroid stimulating hormone beta subunit and changes in activity of the pituitarythyroid axis during silvering of the Japanese eel. J Mol Endocrinol. 2004; 32(1):179-94. https://doi.org/10.1677/jme.0.0320179.

86. Gorbman A. Early development of the hagfish pituitary gland: evidence for the endodermal origin of the adenohypophysis. Am Zool. 1983;23(3):63954. https://doi.org/10.1093/icb/23.3.639.

87. Company R, Astola A, Pendón C, Valdivia MM, Pérez-Sánchez J. Somatotropic regulation of fish growth and adiposity: growth hormone (GH) and somatolactin (SL) relationship. Comp Biochem Phys C. 2001;130(4): 435-45. https://doi.org/10.1016/S1532-0456(01)00269-1.

88. Whittington $\mathrm{CM}$, Wilson $\mathrm{AB}$. The role of prolactin in fish reproduction. Gen Comp Endcor. 2013;191(2):123-36. https://doi.org/10.1016/j.ygcen.2013.05.027.

89. Sundararaj BI, Goswami SV. 'Seminal vesicle'response of intact, castrate, and hypophysectomized catfish, Heteropneustes fossilis (Bloch), to testosterone propionate, prolactin, and growth hormone. Gen Comp Endcor. 1965;5(4): 464-74. https://doi.org/10.1016/0016-6480(65)90107-3.

90. Van AP, Buys N, Onagbesan OM, Decuypere E. Complementary. DNA cloning and Ontogenic expression of pituitary-specific transcription factor of chickens (Gallus domesticus) from the pituitary gland. Gen Comp Endocr. 2006;120(2):127-36.
91. Miyai S, Yoshimera S, Iwasaki Y, Takeokoshi S, Llyod RV, Osamua RY. Induction of GH, PRL and TSH beta mRNA by transfection of PIT-1 in a human pituitary adenine derived cell line. Cell Tissue Res. 2015;322(8):269-77.

92. Farhud D, Aryan Z. Circadian rhythm, lifestyle and health: a narrative review. Iran J Public Health. 2018;47(8):1068-76.

93. Saini R, Jaskolski M, Davis SJ. Circadian oscillator proteins across the kingdoms of life: structural aspects. BMC Biol. 2019;17(1):1-39. https://doi. org/10.1186/s12915-018-0623-3.

94. Zhdanova IV, Reebs SG. Circadian rhythms in fish. Fish Physiol. 2006;24(1):197.

95. Cai W, UdJ RB, Teboul M, Masse I, Pongratz I. Expression levels of estrogen receptor $\beta$ are modulated by components of the molecular clock. Mol Cell Biol. 2008;28(2):22-22. https://doi.org/10.1128/MCB.00233-07.

96. Nakamura TJ, Sellix MT, Menaker M, Block GD. Estrogen directly modulates circadian rhythms of PER2 expression in the uterus. Am J Physiol-Endoc M. 2008;295(5):1025-31. https://doi.org/10.1152/ajpendo.90392.2008.

97. Mostafaie N, Kállay E, Sauerzapf E, Bonner E, Krugluger W. Correlated downregulation of estrogen receptor beta and the circadian clock gene Per1 in human colorectal cancer. Mol Catcinogen. 2009;48(7):642-7. https://doi. org/10.1002/mc.20510.

98. Damdimopoulou P, Nurmi T, Salminen A, Damdimopoulos AE, Kotka M, Paul $V L$, et al. A single dose of enterolactone activates estrogen signaling and regulates expression of circadian clock genes in mice. J Nutr. 2011; 141(9):1583-9. https://doi.org/10.3945/jn.111.140277.

99. Hatcher KM, Royston SE, Mahoney MM. Modulation of circadian rhythms through estrogen receptor signaling. Eur J Neurosci. 2020;51(1):217-28. https://doi.org/10.1111/ejn.14184.

100. Zhao Y, Zhang K, Fent K. Regulation of zebrafish (Danio rerio) locomotor behavior and circadian rhythm network by environmental steroid hormones. Environ Pollut. 2018;232(1):422-9. https://doi.org/10.1016/j. envpol.2017.09.057.

101. Chi Z, Melendez AJ. Role of cell adhesion molecules and immune-cell migration in the initiation, on set and development of atherosclerosis. Cell Adhes Migr. 2007;10(4):171-5. https://doi.org/10.4161/cam.1.4.5321.

102. Dustin ML. Cell adhesion molecules and actin cytoskeleton at immune synapses and kinapses. Curr Opin Cell Biol. 2007;19(5):529-33. https://doi. org/10.1016/j.ceb.2007.08.003.

103. Plata-Salamán CR. Immunoregulators in the nervous system. Neurosci Biobehav R. 1991;15(2):185-215. https://doi.org/10.1016/S0149-7634 (05)80001-6.

104. Silverman HA, Dancho M, Regnier-Golanov A, Nasim M, Pavlov VA. Brain region-specific alterations in the gene expression of cytokines, immune cell markers and cholinergic system components during peripheral endotoxininduced inflammation. Mol Med. 2014;20(1):601-11. https://doi.org/10.2119/ molmed.2014.00147

105. Hu P, Liu B, Meng Z, Liu X, Jia Y, Yang Z, et al. Recovery of gonadal development in tiger puffer Takifugu rubripes after exposure to 17ß-estradiol during early life stages [J]. Chin J Oceanol Limnol. 2017;35(3):613-23. https://doi.org/10.1007/s00343-017-6016-6.

106. Anders S, Huber W. Differential expression analysis for sequence count data. Genome Biol. 2010;11(3):106. https://doi.org/10.1186/gb-2010-11-10-r106.

\section{Publisher's Note}

Springer Nature remains neutral with regard to jurisdictional claims in published maps and institutional affiliations.

Ready to submit your research? Choose BMC and benefit from:

- fast, convenient online submission

- thorough peer review by experienced researchers in your field

- rapid publication on acceptance

- support for research data, including large and complex data types

- gold Open Access which fosters wider collaboration and increased citations

- maximum visibility for your research: over $100 \mathrm{M}$ website views per year

At BMC, research is always in progress.

Learn more biomedcentral.com/submissions 